\title{
Two Cassava Basic Leucine Zipper (bZIP) Transcription Factors (MebZIP3 and MebZIP5) Confer Disease Resistance against Cassava Bacterial Blight
}

\author{
Xiaolin $\mathrm{Li}^{1+}$, Shuhong Fan ${ }^{1+}$, Wei Hu${ }^{2 t}$, Guoyin $\mathrm{Liu}^{1}$, Yunxie Wei ${ }^{1}$, Chaozu He${ }^{1 *}$ and \\ Haitao Shi ${ }^{*}$ \\ ${ }^{1}$ Hainan Key Laboratory for Sustainable Utilization of Tropical Bioresources and College of Biology, Institute of Tropical \\ Agriculture and Forestry, Hainan University, Haikou, China, ${ }^{2}$ Key Laboratory of Biology and Genetic Resources of Tropical \\ Crops, Institute of Tropical Bioscience and Biotechnology, Chinese Academy of Tropical Agricultural Sciences, Haikou, China
}

\section{OPEN ACCESS}

Edited by:

Jacqueline Batley,

University of Western Australia,

Australia

Reviewed by:

Zhaoging Chu,

Shanghai Chenshan Plant Science

Research Center (CAS), China

Hye Sun Cho,

Korea Research Institute

of Bioscience \& Biotechnology,

South Korea

*Correspondence:

Haitao Shi

haitaoshi@hainu.edu.cn

Chaozu He

czhe@hainu.edu.cn

tThese authors have contributed equally to this work.

Specialty section:

This article was submitted to

Plant Breeding,

a section of the journal

Frontiers in Plant Science

Received: 06 August 2017 Accepted: 27 November 2017 Published: 08 December 2017

Citation:

Li X, Fan S, Hu W, Liu G, Wei Y, He C and Shi H (2017) Two Cassava

Basic Leucine Zipper (bZIP)

Transcription Factors (MebZIP3 and MebZIP5) Confer Disease

Resistance against Cassava Bacterial Blight. Front. Plant Sci. 8:2110. doi: 10.3389/fp/s.2017.02110
Basic domain-leucine zipper (bZIP) transcription factor, one type of conserved gene family, plays an important role in plant development and stress responses. Although 77 MebZIPs have been genome-wide identified in cassava, their in vivo roles remain unknown. In this study, we analyzed the expression pattern and the function of two MebZIPs (MebZIP3 and MebZIP5) in response to pathogen infection. Gene expression analysis indicated that MebZIP3 and MebZIP5 were commonly regulated by flg22, Xanthomonas axonopodis pv. manihotis (Xam), salicylic acid (SA), and hydrogen peroxide $\left(\mathrm{H}_{2} \mathrm{O}_{2}\right)$. Subcellular localization analysis showed that MebZIP3 and MebZIP5 are specifically located in cell nucleus. Through overexpression in tobacco, we found that MebZIP3 and MebZIP5 conferred improved disease resistance against cassava bacterial blight, with more callose depositions. On the contrary, MebZIP3- and MebZIP5silenced plants by virus-induced gene silencing (VIGS) showed disease sensitive phenotype, lower transcript levels of defense-related genes and less callose depositions. Taken together, this study highlights the positive role of MebZIP3 and MebZIP5 in disease resistance against cassava bacterial blight for further utilization in genetic improvement of cassava disease resistance.

Keywords: basic leucine zipper (bZIP) transcription factor, cassava (Manihot esculenta), cassava bacterial blight, disease resistance, virus-induced gene silencing (VIGS)

\section{INTRODUCTION}

The genus Xanthomonas is a kind of plant pathogen that infects a wide range of plant species, including rice, pepper, tomato, citrus, and Nicotiana benthamiana. Xam is the causal pathogen of cassava bacterial blight, resulting in leaf wilting, shoot dieback, and stem vascular necrosis (McCallum et al., 2017). Cassava is one major tropical crop; however, its yield is seriously affected

Abbreviations: bHLH, basic helix-loop-helix; bZIP, basic domain-leucine zipper; DAPI, 4',6-diamidino-2-phenylindole; dpi, days post infiltration; ERFs, ethylene-responsive element-binding factors; GFP, green fluorescent protein; $\mathrm{H}_{2} \mathrm{O}_{2}$, hydrogen peroxide; LSD1, lesions simulating disease resistance 1; NO, nitric oxide; NPR1, non-expresser of PR genes; POX, peroxidase; PR1, pathogenesis-related gene 1; ROS, reactive oxygen species; SA, salicylic acid; SC124, South China 124; TGA, TGACGTCA cis-element-binding protein; VIGS, virus-induced gene silencing; WT, wild type; Xam, Xanthomonas axonopodis pv. manihotis; ZFPs, zinc finger proteins. 
by cassava bacterial blight (Pereiral et al., 2003; Camilo et al., 2005; Quintero et al., 2013; Muñoz-Bodnar et al., 2014). To date, the molecular mechanism underlying cassava in response to bacterial blight is largely unknown, and the identification and utilization of disease-related genes are very limited. With the public available cassava genome sequence (Wang et al., 2014), more and more researches start to isolate cassava genes and investigate their role in stress response, starch metabolism, and postharvest physiological deterioration of cassava storage roots (Okogbenin et al., 2013; Xu et al., 2013; Zeng et al., 2014; Zhao et al., 2015; Wei et al., 2016). Although some disease resistant cassava varieties have been identified (Boher and Verdier, 1994; Wydra et al., 2007), functional characterization of disease-related genes remains limited.

The bZIP transcription factor, one type of conserved gene family, plays an important role in plant growth, development, abiotic and biotic stress responses (Alves et al., 2013; E et al., 2014). With the conserved bZIP domain, bZIP family is one of the largest transcription factors in plants. The bZIP domain contains two structural features, a basic region and a leucine zipper (Alagarasan et al., 2017; Zha et al., 2017). The basic region consists of about 16 amino acid residues and an invariant $\mathrm{N}-\mathrm{x} 7$ $\mathrm{R} / \mathrm{K}$ motif, which are responsible for nuclear localization and DNA binding, respectively. The leucine zipper includes a heptad repeat of leucines or other bulky hydrophobic amino acids that are positioned exactly nine amino acids toward the C-terminus, forming a superimposing coiled-coil structure (Alves et al., 2013; E et al., 2014). So far, plant bZIP transcription factors preferentially bind to DNA sequences with a core motif of ACGT, such as A-box (TACGTA), C-box (GACGTC), and G-box (CACGTG) (Foster et al., 1994; Sibéril et al., 2001; Jakoby et al., 2002; Schütze et al., 2008).

Through genome-wide analysis, bZIP gene family has been identified in numerous plant species, including Arabidopsis (Jakoby et al., 2002), pepper (Capsicum annum) (Hwang et al., 2005), rice (Oryza sativa L.) (Nijhawan et al., 2008), maize (Zea mays L.) (Wei et al., 2012), Populus (Ji et al., 2013), Phaseolus vulgaris (Astudillo et al., 2013), castor bean (Ricinus communis L.) (Jin et al., 2014), grapevine (Vitis vinifera) (Liu et al., 2014), cucumber (Cucumis sativus) (Baloglu et al., 2014), Brassica rapa (Hwang et al., 2014), barley (Hordeum vulgare L.) (Pourabed et al., 2015), Brachypodium distachyon (Liu and Chu, 2015), tomato (Solanum lycopersicum L.) (Li et al., 2015), legume (Lablab purpureus L.) (Wang et al., 2015), cassava (Manihot esculenta) (Hu et al., 2016), apple (Malus sieversii L.) (Zhao et al., 2016), and cabbage (Brassica oleracea) (Bai et al., 2016). Functional analysis found that plant bZIPs are widely involved in metabolism (Hartmann et al., 2015; Zhang et al., 2015; Sagor et al., 2016), abiotic stress (salt, drought) (Inaba et al., 2015; Moon et al., 2015; Sornaraj et al., 2016; Xu et al., 2016; Zong et al., 2016; Banerjee and Roychoudhury, 2017) and plant-pathogen interaction (Kim and Delaney, 2002; Shearer et al., 2012; Alves et al., 2013, 2015; Lim et al., 2015).

As transcription factors, plant bZIPs regulate down-stream genes through directly binding to their promoter regions (Foster et al., 1994; Sibéril et al., 2001; Jakoby et al., 2002; Schütze et al., 2008). TGA is widely known in plant defense responses. In Arabidopsis, TGAs interact with NPR1, and binding to the promoters of SA-responsive genes such as PR1 (Alves et al., 2013). Moreover, plant bZIPs regulate disease resistance through interacting with other proteins in defense responses, including the interaction of AtbZIP10 and LSD1 (Kaminaka et al., 2006), NtTGAs and NtWRKY12 (van Verk et al., 2011). Although 77 MebZIPs have been genome-wide identified in cassava (Hu et al., 2016), their in vivo role remains unknown. In this study, the expression pattern and gene function of two MebZIPs (MebZIP3 and MebZIP5) in response to pathogen infection were analyzed. We highlight the positive role of MebZIP3 and MebZIP5 in disease resistance against cassava bacterial blight for further utilization in genetic improvement of cassava resistance to disease.

\section{MATERIALS AND METHODS}

\section{Plant Materials and Growth Conditions}

South China 124 variety of Manihot esculenta was used. SC124 cassava and tobacco plants were grown in soil with Hoagland's solution, at $26-28^{\circ} \mathrm{C}$, with $12 \mathrm{~h}$ light at $120-150 \mu \mathrm{mol}$ quanta $\mathrm{m}^{-2} \mathrm{~s}^{-1}$ irradiance and $12 \mathrm{~h}$ dark cycles.

\section{RNA Isolation and Quantitative Real-Time PCR}

Total RNA extraction and cDNA synthesis were performed from plant leaves using RNAprep Pure Plant Kit (TIANGEN, DP441, Beijing, China) and RevertAid First Strand cDNA Synthesis Kit (Thermo Scientific, K1622, Waltham, MA, United States), according to the manufacturer's instruction. The quantitative real-time PCR was performed using cDNA and FastStart Essential DNA Green Master (Roche, 06924204001, Basel, Switzerland) and analyzed using the comparative $\Delta \Delta^{C_{\mathrm{T}}}$ method as Wei et al. (2016) described. NtEF1a and MeEF1a were used as internal references for analysis. The primers used for real-time PCR were listed in Supplementary Table S1.

\section{Vector Construction and Transient Expression in Nicotiana benthamiana Leaves}

For the vector construction, the coding regions of MebZIP3 and MebZIP5 were first amplified by PCR from plant leave samples. Thereafter, the PCR products were cloned into SpeI and NcoI/SpeI digested modified pCAMBIA1302 (Liu et al., 2015) by restriction enzyme digestion and $T_{4}$ ligase ligation, respectively. The primers responsible for vector constructs were listed in Supplementary Table S2, and the restriction enzymes and their cutting sites were marked. The vector cassettes were illustrated in Supplementary Figure S1. After DNA sequencing for confirmation, the recombinant plasmids as well as P19 were transformed into Agrobacterium tumefaciens strain GV3101. After syringe infiltrating into Nicotiana benthamiana leaves as Sparkes et al. (2006) described for $2 \mathrm{dpi}$, the green fluorescent 
and DAPI-stained cell nuclei in the infiltrated leaf areas were examined using a confocal laser-scanning microscope (TCS SP8, Leica, Heidelberg, Germany).

\section{Generation of Transgenic Tobacco Plants}

The transgenic MebZIP3 and MebZIP5 tobacco plants were generated through Agrobacterium-mediated transformation of MebZIP3-pCAMBIA1302 and MebZIP5-pCAMBIA1302 as Horsch et al. (1985) described. Briefly, 14-day-old sterilized tobacco leaves were incubated in Agrobacterium cell suspension for $10 \mathrm{~min}$. Subsequently, the treated leaves were dried with sterilized tissue paper and placed on full MS-Agar medium for co-cultivation. After 2 days, the leaves were transferred to shoot initiation medium with cephalosporin $\left(250 \mathrm{mg} \mathrm{L}^{-1}\right)$ and hygromycin (50 $\mathrm{mg} \mathrm{L}^{-1}$ ) and the surviving seedlings were grown in a greenhouse to produce seeds for further analysis. The $\mathrm{T}_{2}$ transgenic seedlings were selected on MS medium with $50 \mathrm{mg} \mathrm{L}^{-1}$ hygromycin, and the green seedlings with long roots were transferred to soil for further semiquantitative reverse transcriptase-PCR and seed harvest. The transgenic $\mathrm{T}_{3}$ seedlings were further selected on MS medium with $50 \mathrm{mg} \mathrm{L}^{-1}$ hygromycin to obtain homozygous lines with no segregation on hygromycin resistance, and the independent transgenic $\mathrm{T}_{3}$ lines were used for phenotype analysis.

\section{Virus-Induced Gene Silencing (VIGS) in Cassava}

For the vector construction, the partial coding regions of MebZIP3 and MebZIP5 were first amplified by PCR from plat leave samples. Thereafter, the PCR products of these genes were cloned into EcoRI/BamHI digested pTRV2 vector (Liu et al., 2002) by restriction enzyme digestion and $\mathrm{T}_{4}$ ligase ligation. The primers that are responsible for vector constructs were listed in Supplementary Table S2, the restriction enzymes and their cutting sites were marked. The vector cassettes were illustrated in Supplementary Figure S1. After DNA sequencing for confirmation, the recombinant plasmid (pTRV2-MebZIP3 and pTRV2-MebZIP5) as well as pTRV1 were transformed into Agrobacterium tumefaciens strain GV3101. The GV3101 strains were first cultured in $10 \mathrm{ml}$ of $\mathrm{LB}$ liquid medium at $28^{\circ} \mathrm{C}$ for $12 \mathrm{~h}$, and shaken in the new LB liquid culture to reached $\mathrm{OD}_{600}$ at about 2. After diluted to $\mathrm{OD}_{600}$ of 1 by $10 \mathrm{mM} \mathrm{MgCl}_{2}$, $10 \mathrm{mM}$ MES, and $20 \mathrm{mM}$ acetosyringone, the GV3010 strain with pTRV1 and the strain with pTRV2 or MebZIP3-pTRV2 or MebZIP5-pTRV2 were mixed with ratio of 1:1 and co-infiltrated into cassava leaves as Wei et al. (2017) described. After 14 days, the corresponding gene expression assay and disease resistance assay were performed in plant leaves.

\section{Xam Infection}

The bacterial pathogen of Xam was first cultured in $10 \mathrm{ml}$ of $\mathrm{LB}$ liquid medium at $28^{\circ} \mathrm{C}$ for $12 \mathrm{~h}$, and shaken in the new $\mathrm{LB}$ liquid culture to reach $\mathrm{OD}_{600}$ at about 0.6. After diluted to $10^{8} \mathrm{cfu} \mathrm{ml}^{-1}$ by $10 \mathrm{mM} \mathrm{MgCl}_{2}$ and $0.05 \%$ silwet L-77, the Xam was syringe infiltrated into abaxial side of

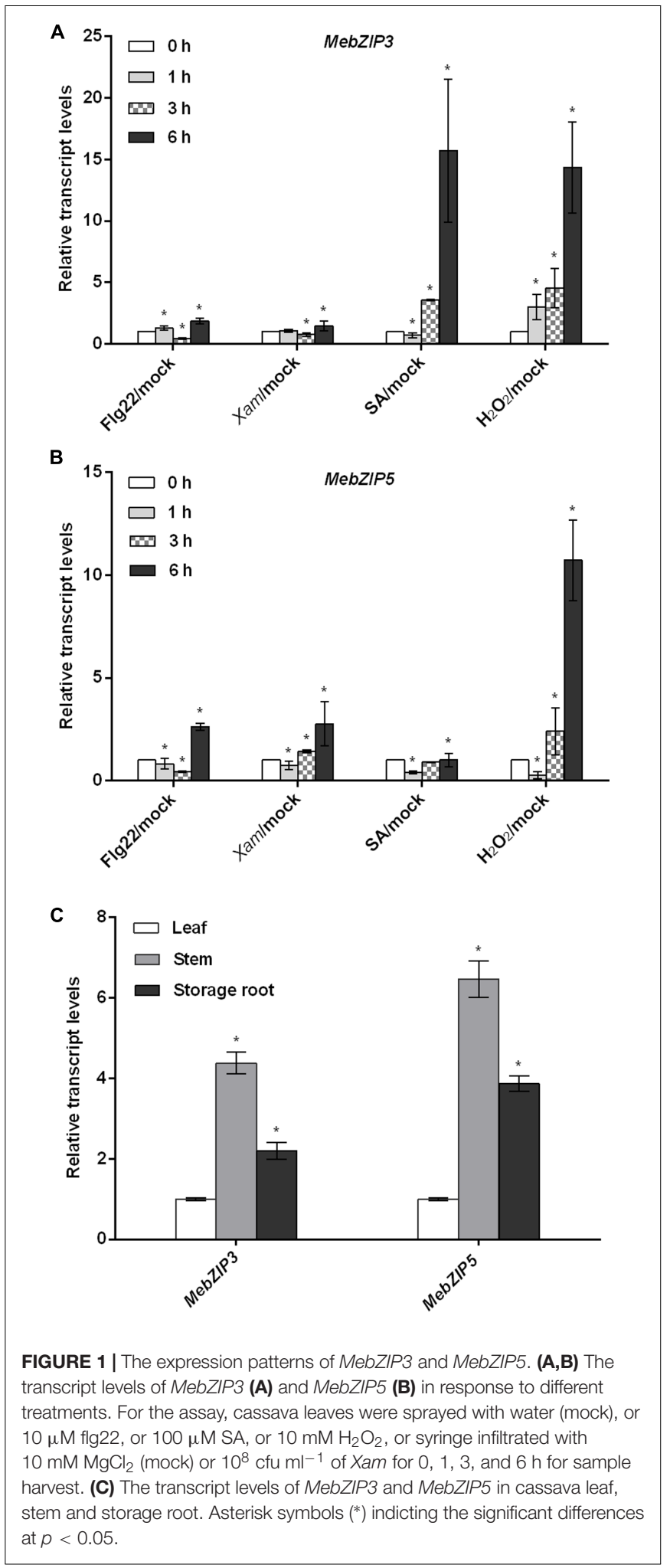

plant leaves. Then the plants with pathogen infection were grown in the green house. At indicated time-points, at least 20 leaves were harvested in every biological repeat. Plant leaves were gently washed by sterile distilled water for $1 \mathrm{~min}$, 


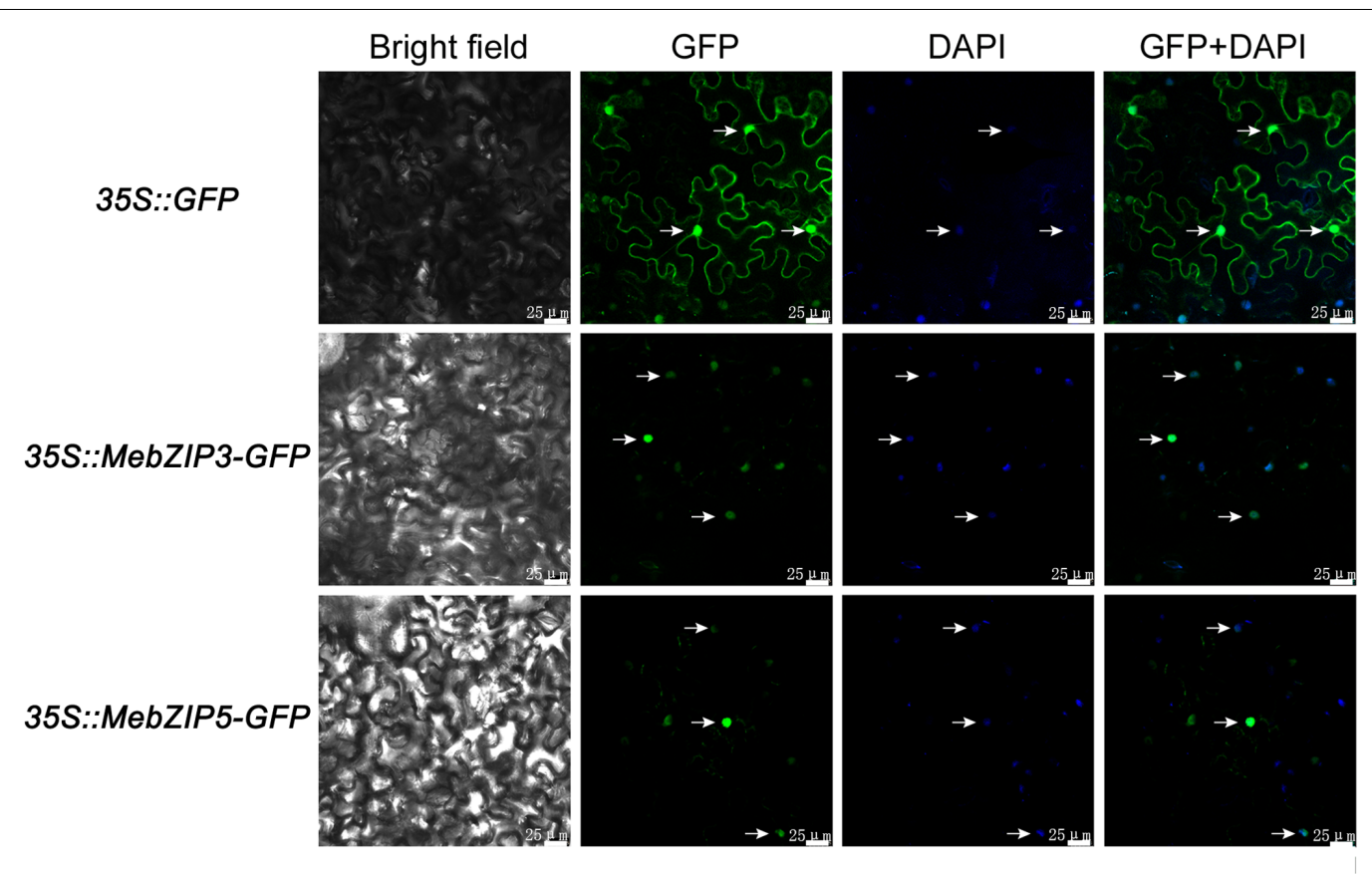

FIGURE 2 | Subcellular localization of MebZIP3 and MebZIP5 in Nicotiana benthamiana leaves. After 2 dpi in Nicotiana benthamiana leaves, green fluorescent with green color and DAPI-stained cell nuclei with blue color were examined using a confocal laser-scanning microscope. The co-localization of GFP with DAPI was marked by arrow. Bars $=25 \mu \mathrm{m}$.

A

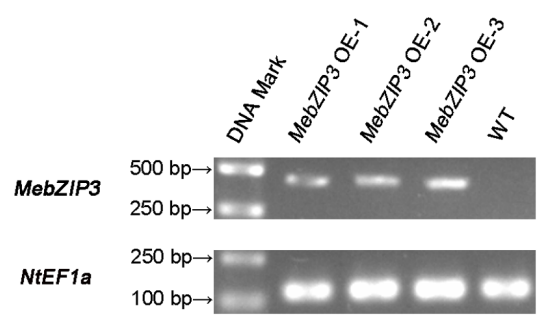

B

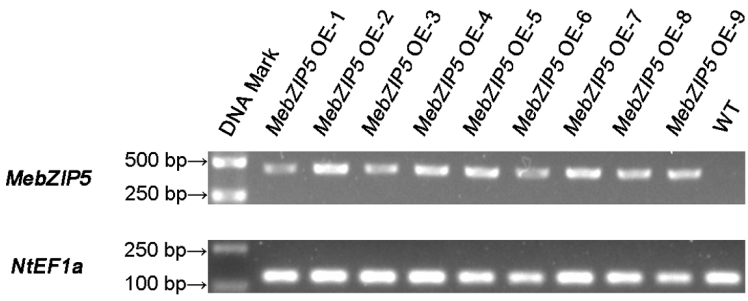

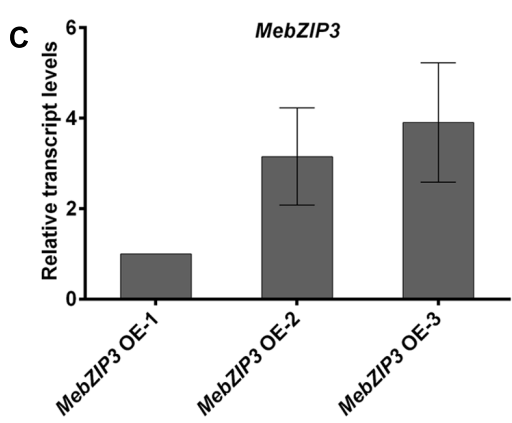

D

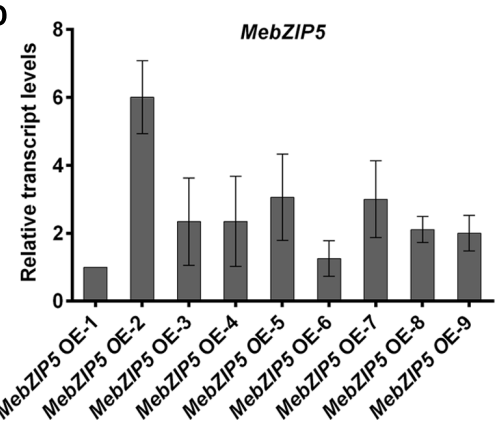

FIGURE 3 | Isolation of MebZIP3 and MebZIP5 overexpressing plants in Nicotiana benthamiana. (A,B) Confirmation of the gene expression in overexpressing lines by semi-quantitative reverse transcriptase-PCR. The expression of NtEF1a was used as the internal control. (C,D) The relative transcript levels in overexpressing lines by quantitative real-time PCR. Asterisk symbols (*) indicting the significant differences in comparison to mock treatment at $p<0.05$. 


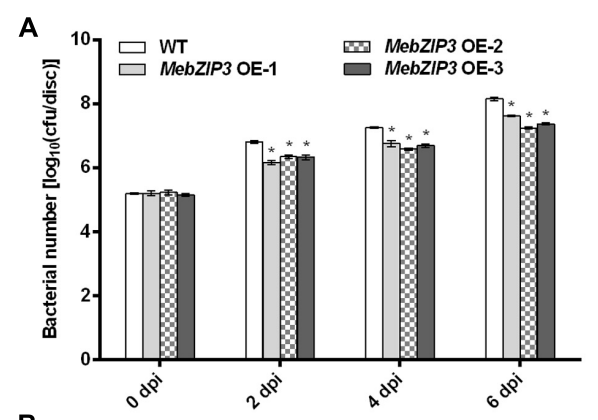

B
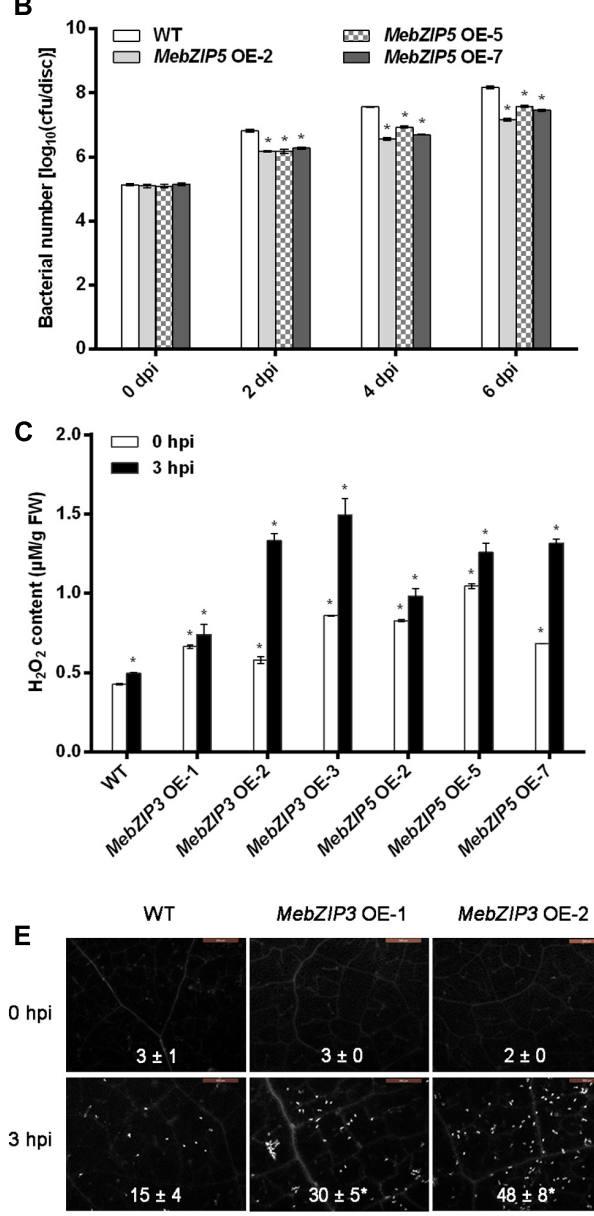
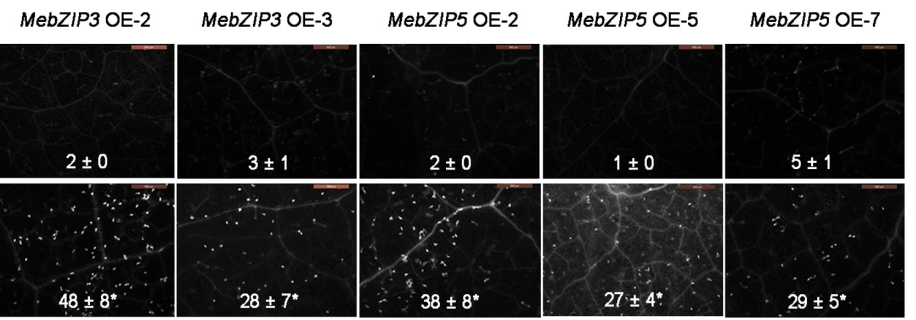

FIGURE 4 | Overexpression of MebZIP3 and MebZIP5 confers improved disease resistance against cassava bacterial blight. (A,B) The bacterial number of Xam in WT, MebZIP3 (A) and MebZIP5 (B) transgenic plant leaves at 0, 2, 4, and 6 dpi of $10^{8} \mathrm{cfu} \mathrm{ml}^{-1}$ of Xam. (C) The pictures showing the plant leaves at 0 and 6 dpi of Xam. Bars $=1 \mathrm{~cm}$. (D) Quantification of $\mathrm{H}_{2} \mathrm{O}_{2}$ in plant leaves. (E) The callose depositions in plant leaves. White dots in the figures indicated callose depositions in plant leaves, and the average data was shown. At least 15 cassava leaves were assayed for every biological repeat, and at least three biological repeats were performed. Asterisk symbols $(*)$ indicting the significant differences in comparison to WT at $p<0.05$.

then the bacterial populations in plant leaves were quantified using $10 \mu \mathrm{l}$ five 10-fold dilutions of homogenate in LB medium.

\section{Callose Staining}

Callose deposition in plant leaves was visualized by callose staining, using alcoholic lactophenol solution, $0.01 \%(\mathrm{w} / \mathrm{v})$ aniline blue solution, 50\% (v/v) glycerol and fluorescence microscope (DM6000B, Leica, Heidelberg, Germany) as Hauck et al. (2003) described.

\section{Reactive Oxygen Species (ROS) Quantification}

The endogenous levels of $\mathrm{H}_{2} \mathrm{O}_{2}$ in plant leaves were extracted and determined using the peroxide-titanium buffer as Wei et al. (2016) previously described. 


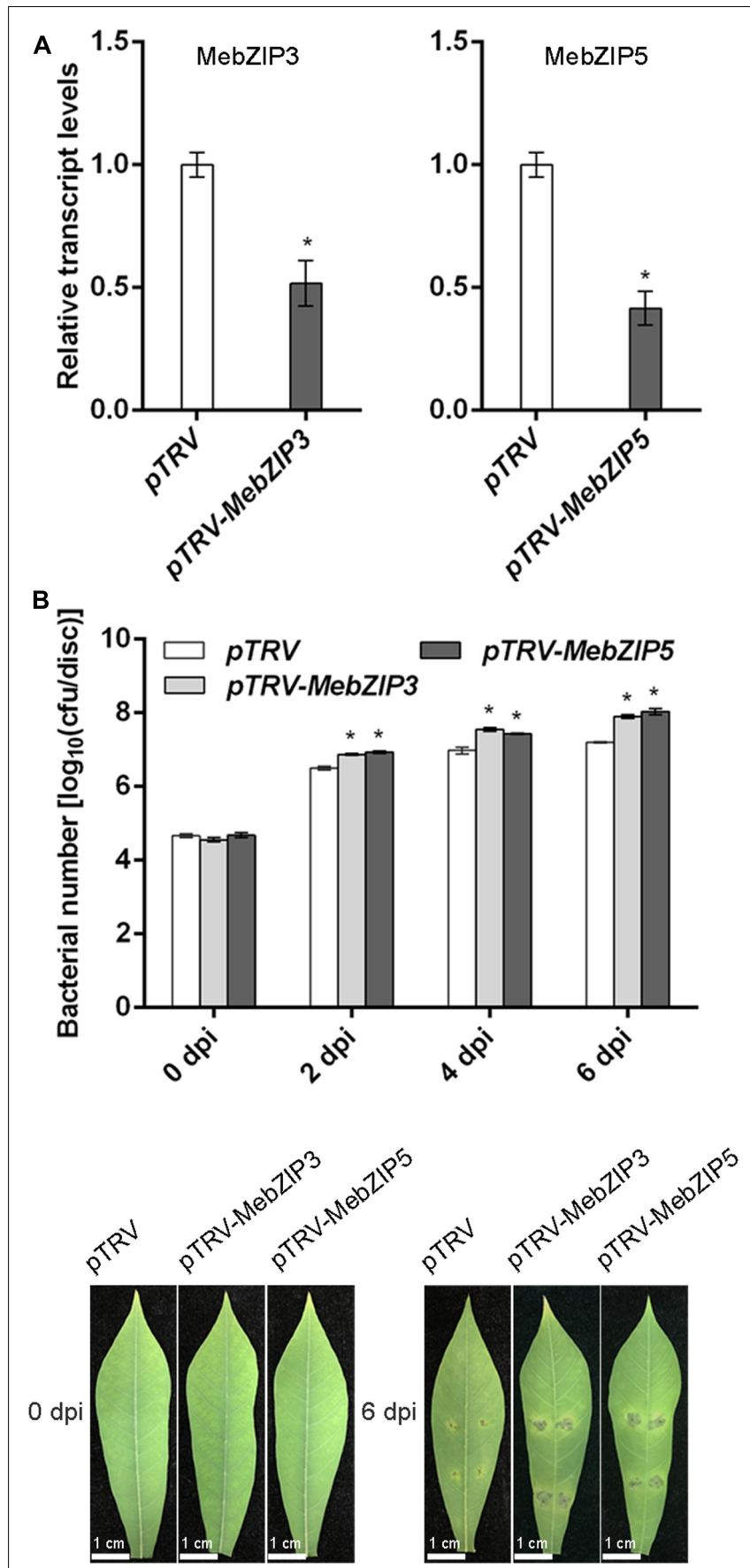

FIGURE 5 | MebZIP3- and MebZIP5-silenced plants result in disease sensitive. (A) The gene transcript levels of MebZIP3 and MebZIP5 in the VIGS plants. (B) The bacterial number of Xam in WT, MebZIP3- and MebZIP5-silenced plant leaves at 0, 2, 4, and 6 dpi of $10^{8} \mathrm{cfu} \mathrm{ml}^{-1}$ of Xam. For the assay, Agrobacterium tumefaciens strains with the recombinant plasmid (pTRV2-MebZIP3 and pTRV2-MebZIP5) as well as pTRV1 were syringe infiltrated into cassava leaves for 14 days, thereafter the corresponding gene expression assay and disease resistance assay were performed. The cassava leaves were syringe infiltrated by $10^{8} \mathrm{cfu} \mathrm{ml}^{-1}$ of Xam for another 0 , 2, 4, 6 days, and the bacterial number in the cassava leaves were quantified At least 15 cassava leaves were assayed for every biological repeat, and at least three biological repeats were performed. Asterisk symbols $\left(^{*}\right)$ indicting the significant differences in comparison to vector transformation at $p<0.05$.

\section{Transcriptional Activation Assay in Yeast Cells}

For the vector construction, the coding regions of MebZIP3 and MebZIP5 were first amplified by PCR from plant leave samples. Thereafter, the PCR products of these were cloned into NdeI/BamHI and NcoI/BamHI digested pGBKT7 by restriction enzyme digestion and $T_{4}$ ligase ligation, respectively. The primers that are responsible for vector constructs were listed in Supplementary Table S2, the restriction enzymes and their cutting sites were marked. After DNA sequencing for confirmation, the recombinant plasmids were transformed into yeast strain AH109, according to the manufacturer's protocol (Clontech, United States). The transformed clones were screened on the $\mathrm{SD} /$-Trp and $\mathrm{SD} /$-His mediums, respectively. The transcriptional activation was evidenced by the growth of yeast cells on $\mathrm{SD} /$-His medium with $5 \mathrm{mM} \mathrm{X}-\alpha$-gal at $30^{\circ} \mathrm{C}$ for 3 days.

\section{Accession Numbers}

The accession numbers and CDS length of all genes are shown as following: MebZIP3 (KU160294, 1,788 bp), MebZIP5 (KU160296, 1,488 bp), MePR1 (Me07G050300, 492 bp), MePR2 (Me10G089800, 492 bp), MePR3 (Me07G050700, 486 bp), MePR4 (Me07G050400, 492 bp), MeEF1a (AF041463, 1,035 bp), NtEF1a (AY206004, 661 bp).

\section{Statistical Analysis}

All results in this study were obtained from at least three biological repeats, and the average values and SDs of these biological repeats were shown. In the meanwhile, asterisk symbols $(*)$ indicting the significant differences at $p<0.05$ were also shown after ANOVA analysis.

\section{RESULTS}

\section{Expression Profiles of MebZIP3 and MebZIP5 in Response to Stress Treatments}

In the previous study (Hu et al., 2016), 77 MebZIPs have been identified in Manihot esculenta Phytozome database v10.3 ${ }^{1}$. Herein, a phylogenetic tree between MebIP3/MebZIP5 and their homologs from other plant species were constructed (Supplementary Figure S2A), and the results implied the functional similarities among the bZIP proteins in different plants. Moreover, the conserved bZIP domain of MebZIP3 and MebZIP5 was identified (Supplementary Figure S2B), further indicating that bZIPs are conserved during evolution.

Using quantitative real-time PCR, we found that the transcript levels of MebZIP3 and MebZIP5 were significantly regulated after flg22, Xam, SA and $\mathrm{H}_{2} \mathrm{O}_{2}$ treatments (Figures 1A,B). After flg22 treatment, the transcript levels of MebZIP3 and MebZIP5 were down-regulated at $3 \mathrm{~h}$, but largely up-regulated at $6 \mathrm{~h}$. After Xam treatment, MebZIP3 and MebZIP5 transcripts were significantly induced at $6 \mathrm{~h}$. MebZIP3 transcript was largely increased after SA

${ }^{1}$ https://phytozome.jgi.doe.gov 

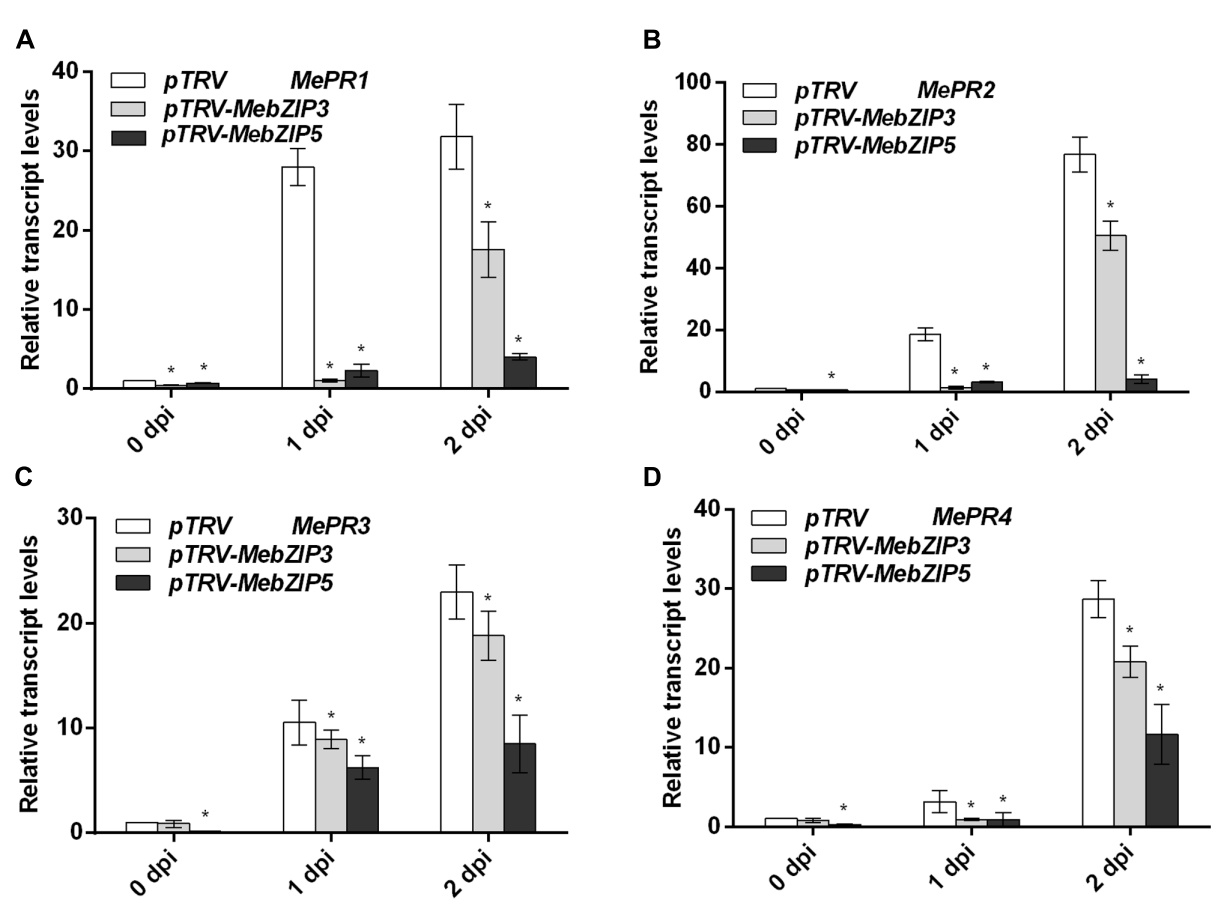

FIGURE 6 | Silencing of MebZIP3- and MebZIP5 regulates the transcripts of defense-related genes. (A-D) The relative transcript levels of MePR1 (A), MePR2 (B), MePR3 (C), and MePR4 (D) in the gene silenced plants. At least 15 cassava leaves were assayed for every biological repeat, and at least three biological repeats were performed. Asterisk symbols $\left(^{*}\right)$ indicting the significant differences in comparison to vector transformation at $p<0.05$.

treatment for 3 and $6 \mathrm{~h}$, while MebZIP5 expression was decreased after SA treatment for $1 \mathrm{~h}$. Moreover, MebZIP3 and MebZIP5 transcripts were largely induced after $\mathrm{H}_{2} \mathrm{O}_{2}$ treatment for 3 and $6 \mathrm{~h}$ (Figures 1A,B). Generally, the transcripts of MebZIP3 and MebZIP5 displayed common expression patterns in response to these treatments, indicating the possible involvement of them in plant disease response. Moreover, we found that MebZIP3 and MebZIP5 were expressed in all assayed organs, with higher transcript levels in cassava stem and storage root than in leaf (Figure 1C).

\section{Subcellular Localization of MebZIP3 and MebZIP5}

To investigate the subcellular location of MebZIP3 and MebZIP5, the coding regions of these genes were fused with GFP and transiently expressed in Nicotiana benthamiana leaves. The control vector (35S::GFP)-transformed leaves displayed GFP in both cell nuclei and membrane, consistent with many previous studies (Wei et al., 2017). The GFP signals of MebZIP3-GFP and MebZIP5-GFP were co-localized with DAPI-stained cell nuclei in the infiltrated leaf areas, as marked by the arrow, suggesting that MebZIP3 and MebZIP5 are specifically located in cell nucleus (Figure 2).

\section{Transcriptional Activation Assays of MebZIP3 and MebZIP5}

Since bZIPs belongs to transcription factor family, transcription activation assays of MebZIP3 and MebZIP5 were performed in yeast cells. The coding regions of MebZIP3 and MebZIP5 were fused to the GAL4 DNA binding domain in pGBKT7, and the constructs were transformed into yeast strain AH109. As evidenced by the growth of yeast cells and LacZ staining on SD/-His medium with $5 \mathrm{mM} \mathrm{X}$ - $\alpha$-gal, the yeast cells transformed with MebZIP3-pGBKT7 and MebZIP5-pGBKT7 had transcriptional activity (Supplementary Figure S3), suggesting the transcriptional activities of MebZIP3 and MebZIP5 in yeast cells.

\section{Isolation of MebZIP3 and MebZIP5 Overexpressing Plants in Nicotiana benthamiana}

To further reveal the in vivo roles of MebZIP3 and MebZIP5, the transgenic plants overexpressing MebZIP3 or MebZIP5 were generated in tobacco. After selection on MS medium with hygromycin, the resistant $T_{1}$ transgenic seedlings were transferred to soil, and the gene expressions in the overexpressing lines were confirmed by semi-quantitative reverse transcriptase-PCR (Figures 3A,B and Supplementary Figure S4). The corresponding MebZIP3 or MebZIP5 could be examined in the transgenic MebZIP3 or MebZIP5 overexpressing tobacco lines, but could not be amplified in the WT tobacco leaves (Figures 3A,B and Supplementary Figure S4). The transgenic $T_{2}$ and $T_{3}$ seedlings were further selected on MS medium with $50 \mathrm{mg} \mathrm{L}^{-1}$ hygromycin to obtain homozygous lines with no segregation on hygromycin resistance. Because no PCR product was detected in the 


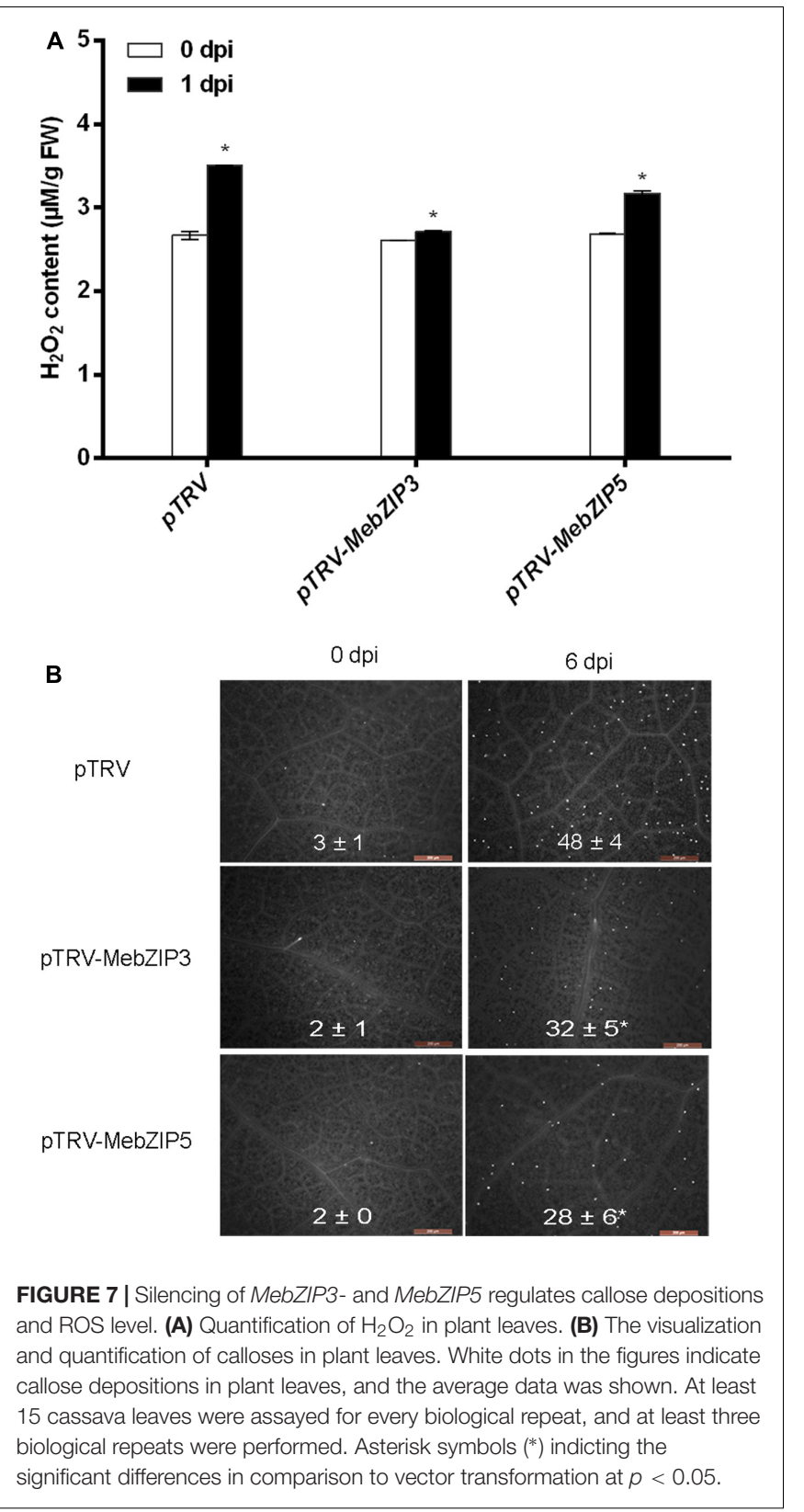

WT sample by semi-quantitative reverse transcriptase-PCR (Figures 3A,B), quantitative real-time PCR was performed to show the relative transcript level in different transgenic $\mathrm{T}_{3}$ lines (Figures 3C,D). Based on the gene transcript level, three independent transgenic $\mathrm{T}_{3}$ lines were used for the phenotype analysis of MebZIP3 (OE1, OE2, and OE3) and MebZIP5 (OE2, OE5, and OE7).

\section{MebZIP3 and MebZIP5 Confer Improved Disease Resistance against Cassava Bacterial Blight}

Although Nicotiana benthamiana is non-host of Xam, its leaves can be infected by Xam with disease symptom and pathogen growth. To investigate the function of MebZIP3 and MebZIP5 in plant disease resistance, the leaf surfaces of WT, MebZIP3, and MebZIP5 transgenic lines were infected with $10^{8} \mathrm{cfu} \mathrm{ml}^{-1}$ of Xam. At 2, 4, and $6 \mathrm{dpi}$, three MebZIP3 (OE1, OE2, and OE3) and three MebZIP5 (OE2, OE5, and OE7) overexpressing lines exhibited significant less bacterial number in the leaves in comparison to that of WT (Figures 4A-C). Moreover, when Xam was infected, the $\mathrm{H}_{2} \mathrm{O}_{2}$ and callose depositions were substantially higher in the overexpressing plant leaves than those in WT (Figures 4D,E). These results suggested that overexpression of MebZIP3 and MebZIP5 conferred improved disease resistance.

To further confirm the in vivo roles of MebZIP3 and MebZIP5 in cassava defense resistance, we construct the MebZIP3and MebZIP5-silenced plants through VIGS. As evidenced by the lower transcript of MebZIP3 or MebZIP5, the VIGS plants ( $p T R V$-MebZIP3 and $p T R V$-MebZIP5) were successfully acquired (Figure 5A). In comparison to mock plants, the VIGS plant ( $p T R V-M e b Z I P 3$ and $p T R V-M e b Z I P 5)$ leaves showed more bacterial number (Figure 5B), lower transcripts of defenserelated genes ( $P R 1, P R 2, P R 3$, and $P R 4)$ (Figure 6), less callose depositions and lower levels of $\mathrm{H}_{2} \mathrm{O}_{2}$ in plant leaves upon Xam infection (Figures 7A,B). Thus, MebZIP3 and MebZIP5 are essential for plant disease resistance in cassava.

\section{DISCUSSION}

Although some aquatic plants can move, most plants live as sessile organisms. When subjected to abiotic stress (soil salinity, drought, and extreme temperature) and pathogen infection, plants have to response and cope with these stressors. In the long time of evolution, plants have developed several stress-signaling pathways, including signal receptor, protein kinase, transcription factor, and downstream genes. In the core stress-signaling pathways, transcription factors (including bHLHs, bZIPs, ERFs, ZFPs, WRKYs, MYBs, MYCs) play important roles in linking upstream protein kinase with downstream gene expression (Alves et al., 2013; Okogbenin et al., 2013; E et al., 2014; Hu et al., 2016).

Although 77 MebZIPs have been identified in cassava recently (Hu et al., 2016), their in vivo roles remain unknown so far. In this study, gene expression analysis showed that MebZIP3 and MebZIP5 were commonly regulated by flg22, Xam, SA, and $\mathrm{H}_{2} \mathrm{O}_{2}$. With the conserved bZIP domain, transcription activity and specific localization in cell nucleus, MebZIP3 and MebZIP5 are confirmed to be transcription factors. Through overexpression in tobacco, we found that MebZIP3 and MebZIP5 conferred improved disease resistance against cassava bacterial blight and more callose depositions. Through VIGS, MebZIP3and MebZIP5-silenced plants resulted in disease sensitive, lower transcripts of defense-related genes and less callose depositions. These results are consistent with previous studies that plant bZIP transcription factors are widely involved in plant-pathogen interaction (Kim and Delaney, 2002; Shearer et al., 2012; Alves et al., 2013, 2015; Lim et al., 2015). Thus, we highlight the positive role of MebZIP3 and MebZIP5 in disease resistance against cassava bacterial blight for further utilization in genetic 
improvement of cassava resistance to disease. As reviewed by Alves et al. (2013), TGA is an important bZIP gene in SA signaling. Under control conditions, NPR1 is retained in the cytoplasm as oligomer through $S$-nitrosylation of NPR1 by NO. When the pathogen is infected, SA induces monomeric NPR1 translocates to the nucleus, and NPR1 interacts with TGA family members (bZIPs), and binds to the promoters of SA-responsive genes such as PR1 (Alves et al., 2013). Although the molecular mechanism of MebZIP-mediated defense response remains elusive, the present study provided strong evidence that MebZIP3 and MebZIP5 are positive regulators of disease resistance against cassava bacterial blight. Plant bZIPs serve as important regulators of defense resistance through two ways. On one hand, plant bZIPs interact with other proteins in defense responses, including the interaction of AtbZIP10 and AtLSD1 (Kaminaka et al., 2006), AtTGAs and AtNPR1 (Alves et al., 2013), and NtTGAs and NtWRKY12 (van Verk et al., 2011). On the other hand, plant bZIPs preferentially bind to DNA sequences with A-box (TACGTA), C-box (GACGTC), and G-box (CACGTG) (Foster et al., 1994; Sibéril et al., 2001; Jakoby et al., 2002; Schütze et al., 2008). Herein, MebZIP3and MebZIP5-silenced plants had significant effects on the transcripts of other $M e P R s$, the clone and analysis of $M e P R s$ promoters will display whether A-box, C-box, and G-box are distributed in these regions. If one of these motifs is distributed in MePRs promoters, the underlying MePRs may be the direct target of MebZIP3 and MebZIP5. Otherwise, the transcripts of MePRs may be affected by MebZIP3 and MebZIP5 indirectly. In further study, the identification of direct targets and interacting proteins of MebZIPs will provide more clues to the underlying mechanism in MebZIPs-mediated defense response in cassava. MebZIP3 and MebZIP5 may interact with other transcription factors to regulate their directly binding to MePRs. As a kind of glucan and plant polysaccharide, callose is directly related with callose-associated cell wall and papillae-associated defense (Hauck et al., 2003). Although the underlying mechanism remains unclear, MebZIP3 and MebZIP5-mediated callose accumulation may also contribute to their effects on disease resistance. Taken together, this is the first study showing the positive effects of MebZIP3 and MebZIP5 in plant disease resistance against cassava bacterial blight.

\section{REFERENCES}

Alagarasan, G., Dubey, M., Aswathy, K. S., and Chandel, G. (2017). Genome wide identification of orthologous ZIP genes associated with zinc and iron translocation in Setaria italica. Front. Plant Sci. 8:775. doi: 10.3389/fpls.2017. 00775

Alves, M. S., Dadalto, S. P., Gonçalves, A. B., De Souza, G. B., Barros, V. A., and Fietto, L. G. (2013). Plant bZIP transcription factors responsive to pathogens: a review. Int. J. Mol. Sci. 14, 7815-7828. doi: 10.3390/ijms14047815

Alves, M. S., Soares, Z. G., Vidigal, P. M., Barros, E. G., Poddanosqui, A. M., Aoyagi, L. N., et al. (2015). Differential expression of four soybean bZIP genes during Phakopsora pachyrhizi infection. Funct. Integr. Genomics 15, 685-696. doi: 10.1007/s10142-015-0445-440

Astudillo, C., Fernandez, A. C., Blair, M. W., and Cichy, K. A. (2013). The Phaseolus vulgaris ZIP gene family: identification, characterization, mapping, and gene expression. Front. Plant Sci. 4:286. doi: 10.3389/fpls.2013.00286

\section{AUTHOR CONTRIBUTIONS}

HS conceived and directed this study, analyzed the data, wrote and revised the manuscript. XL, SF, WH, GL, and YW performed the experiments, analyzed the data, wrote and revised the manuscript. $\mathrm{CH}$ provided suggestions and revised the manuscript. All authors approved the manuscript and the version to be published, and agreed to be accountable for all aspects of the work in ensuring that questions related to the accuracy or integrity of any part of the work are appropriately investigated and resolved.

\section{FUNDING}

This research was supported by the National Natural Science Foundation of China (No. 31760067), the startup funding and the Scientific Research Foundation of Hainan University (No. kyqd1531) to HS.

\section{ACKNOWLEDGMENT}

The authors thank Dr. Chris R. Somerville, Dr. Jie Zhou, Dr. Yanru Hu, and Dr. Jian Tian for sharing their vector plasmids.

\section{SUPPLEMENTARY MATERIAL}

The Supplementary Material for this article can be found online at: https://www.frontiersin.org/articles/10.3389/fpls.2017.02110/ full\#supplementary-material

FIGURE S1 | The vector cassettes in this study.

FIGURE S2 | (A) The phylogenetic tree of MebIP3/5 homologs from other plant species. (B) The conserved bZIP domain of MebZIP3 and MebZIP5. Multiple sequence alignment and phylogenetic tress were performed by Clustalx 1.83 and MEGA5.05.

FIGURE S3 | Transcriptional activation assays of MebZIP3 and MebZIP5 in yeast cells.

FIGURE S4 | The original gel images of gene expressions in MebZIP3 and MebZIP5 overexpressing lines by semi-quantitative reverse transcriptase-PCR.

Bai, Y., Zhu, W., Hu, X., Sun, C., Li, Y., Wang, D., et al. (2016). Genome-wide analysis of the bZIP gene family identifies two ABI5-like bZIP transcription factors, BrABI5a and BrABI5b, as positive modulators of ABA signalling in Chinese cabbage. PLOS ONE 11:e0158966. doi: 10.1371/journal.pone.0158966

Baloglu, M. C., Eldem, V., Hajyzadeh, M., and Unver, T. (2014). Genome-wide analysis of the bZIP transcription factors in cucumber. PLOS ONE 9:e96014. doi: 10.1371/journal.pone.0096014

Banerjee, A., and Roychoudhury, A. (2017). Abscisic-acid-dependent basic leucine zipper (bZIP) transcription factors in plant abiotic stress. Protoplasma 254, 3-16. doi: 10.1007/s00709-015-0920-924

Boher, B., and Verdier, V. (1994). Cassava bacterial blight in Africa: the state of knowledge and implication for designing control strategies. Afr. Crop Sci. J. 4, 505-509.

Camilo, L., Soto, M., and Restrepo, S. (2005). Gene expression profile in response to Xanthomonas axonopodis pv manihotis infection in cassava using a cDNA microarray. Plant Mol. Biol. 57, 393-410. doi: 10.1007/s11103-004-7819-3 
E, Z. G., Zhang, Y. P., Zhou, J. H., and Wang, L. (2014). Mini review roles of the bZIP gene family in rice. Genet. Mol. Res. 13, 3025-3036. doi: 10.4238/2014. April.16.11

Foster, R., Izawa, T., and Chua, N. H. (1994). Plant bZIP proteins gather at ACGT elements. FASEB J. 8, 192-200.

Hartmann, L., Pedrotti, L., Weiste, C., Fekete, A., Schierstaedt, J., Göttler, J., et al. (2015). Crosstalk between two bZIP signaling pathways orchestrates salt-induced metabolic reprogramming in Arabidopsis roots. Plant Cell 27, 2244-2260. doi: 10.1105/tpc.15.00163

Hauck, P., Thilmony, R., and He, S. Y. (2003). A Pseudomonas syringae type III effector suppresses cell wall-based extracellular defense in susceptible Arabidopsis plants. Proc. Natl. Acad. Sci. U.S.A. 100, 8577-8582. doi: 10.1073/ pnas. 1431173100

Horsch, R. B., Fry, J. E., Hoffmann, N. L., Eichholtz, D., Rogers, S. C., and Fraley, R. T. (1985). A simple and general method for transferring genes into plants. Science 227, 1229-1231. doi: 10.1126/science.227.4691.1229

Hu, W., Yang, H., Yan, Y., Wei, Y., Tie, W., Ding, Z., et al. (2016). Genome-wide characterization and analysis of bZIP transcription factor gene family related to abiotic stress in cassava. Sci. Rep. 6:22783. doi: 10.1038/srep22783

Hwang, E. W., Kim, K. A., Park, S. C., Jeong, M. J., Byun, M. O., and Kwon, H. B. (2005). Expression profiles of hot pepper (Capsicum annuum) genes under cold stress conditions. J. Biosci. 30, 657-667. doi: 10.1007/BF02703566

Hwang, I., Jung, H. J., Park, J. I., Yang, T. J., and Nou, I. S. (2014). Transcriptome analysis of newly classified bZIP transcription factors of Brassica rapa in cold stress response. Genomics 104, 194-202. doi: 10.1016/j.ygeno.2014.07.008

Inaba, S., Kurata, R., Kobayashi, M., Yamagishi, Y., Mori, I., Ogata, Y., et al. (2015). Identification of putative target genes of bZIP19, a transcription factor essential for Arabidopsis adaptation to $\mathrm{Zn}$ deficiency in roots. Plant J. 84, 323-334. doi: 10.1111/tpj.12996

Jakoby, M., Weisshaar, B., Droge-Laser, W., Vicente-Carbajosa, J., Tiedemann, J., Kroj, T., et al. (2002). bZIP transcription factors in Arabidopsis. Trends Plant Sci. 7, 106-111. doi: 10.1016/S1360-1385(01)02223-3

Ji, L., Wang, J., Ye, M., Li, Y., Guo, B., Chen, Z., et al. (2013). Identification and characterization of the Populus AREB/ABF subfamily. J. Integr. Plant Biol. 55, 177-186. doi: 10.1111/j.1744-7909.2012.01183.x

Jin, Z., Xu, W., and Liu, A. (2014). Genomic surveys and expression analysis of bZIP gene family in castor bean (Ricinus communis L.). Planta 239, 299-312. doi: 10.1007/s00425-013-1979-1979

Kaminaka, H., Näke, C., Epple, P., Dittgen, J., Schütze, K., Chaban, C., et al. (2006). bZIP10-LSD1 antagonism modulates basal defense and cell death in Arabidopsis following infection. EMBO J. 25, 4400-4411. doi: 10.1038/sj.emboj.7601312

Kim, H. S., and Delaney, T. P. (2002). Over-expression of TGA5, which encodes a bZIP transcription factor that interacts with NIM1/NPR1, confers SAR-independent resistance in Arabidopsis thaliana to Peronospora parasitica. Plant J. 32, 151-163. doi: 10.1046/j.1365-313X.2001.01411.x

Li, D., Fu, F., Zhang, H., and Song, F. (2015). Genome-wide systematic characterization of the bZIP transcriptional factor family in tomato (Solanum lycopersicum L.). BMC Genomics 16:771. doi: 10.1186/s12864-015-1990-1996

Lim, C. W., Baek, W., Lim, S., Han, S. W., and Lee, S. C. (2015). Expression and functional roles of the pepper pathogen-induced bZIP transcription factor CabZIP2 in enhanced disease resistance to bacterial pathogen infection. Mol. Plant Microbe Interact. 28, 825-833. doi: 10.1094/MPMI-10-14-0313-R

Liu, J., Chen, N., Chen, F., Cai, B., Dal Santo, S., Tornielli, G. B., et al. (2014). Genome-wide analysis and expression profile of the bZIP transcription factor gene family in grapevine (Vitis vinifera). BMC Genomics 15:281. doi: 10.1186/ 1471-2164-15-281

Liu, J., Liu, L., Li, Y., Jia, C., Zhang, J., Miao, H., et al. (2015). Role for the banana AGAMOUS-like gene MaMADS7 in regulation of fruit ripening and quality. Physiol. Plant 155, 217-231. doi: 10.1111/ppl.12348

Liu, X., and Chu, Z. (2015). Genome-wide evolutionary characterization and analysis of bZIP transcription factors and their expression profiles in response to multiple abiotic stresses in Brachypodium distachyon. BMC Genomics 16:227. doi: 10.1186/s12864-015-1457-1459

Liu, Y., Schiff, M., and Dinesh-Kumar, S. P. (2002). Virus-induced gene silencing in tomato. Plant J. 131, 777-786. doi: 10.1111/j.1365-313X.2005.02441.x

McCallum, E. J., Anjanappa, R. B., and Gruissem, W. (2017). Tackling agriculturally relevant diseases in the staple crop cassava (Manihot esculenta). Curr. Opin. Plant Biol. 38, 50-58. doi: 10.1016/j.pbi.2017.04.008
Moon, S. J., Han, S. Y., Kim, D. Y., Yoon, I. S., Shin, D., Byun, M. O., et al. (2015). Ectopic expression of a hot pepper bZIP-like transcription factor in potato enhances drought tolerance without decreasing tuber yield. Plant Mol. Biol. 89, 421-431. doi: 10.1007/s11103-015-0378-y

Muñoz-Bodnar, A., Perez-Quintero, A. L., Gomez-Cano, F., Gil, J., Michelmore, R., Bernal, A., et al. (2014). RNAseq analysis of cassava reveals similar plant responses upon infection with pathogenic and non-pathogenic strains of Xanthomonas axonopodis pv. manihotis. Plant Cell Rep. 33, 1901-1912. doi: 10.1007/s00299-014-1667-7

Nijhawan, A., Jain, M., Tyagi, A. K., and Khurana, J. P. (2008). Genomic survey and gene expression analysis of the basic leucine zipper transcription factor family in rice. Plant Physiol. 146, 333-350. doi: 10.1104/pp.107.112821

Okogbenin, E., Setter, T., Ferguson, M., Mutegi, R., Ceballos, H., Olasanmi, B., et al. (2013). Phenotypic approaches to drought in cassava: review. Front. Physiol. 4:93. doi: 10.3389/fphys.2013.00093

Pereiral, L. P., Goodwin, P. H., and Erickson, L. (2003). Cloning of a peroxidase gene from cassava with potential as a molecular marker for resistance to bacterial blight. Braz. Arch. Biol. Technol. 46, 149-154. doi: 10.1590/S151689132003000200002

Pourabed, E., Ghane Golmohamadi, F., Soleymani Monfared, P., Razavi, S. M., and Shobbar, Z. S. (2015). Basic leucine zipper family in barley: genomewide characterization of members and expression analysis. Mol. Biotechnol. 57, 12-26. doi: 10.1007/s12033-014-9797-9792

Quintero, A., Pérez-Quintero, A. L., and López, C. (2013). Identification of ta-siRNAs and cis-nat-siRNAs in cassava and their roles in response tocassava bacterial blight. Genomics Proteomics Bioinformatics 11, 172-181. doi: 10.1016/ j.gpb.2013.03.001

Sagor, G. H., Berberich, T., Tanaka, S., Nishiyama, M., Kanayama, Y., Kojima, S., et al. (2016). A novel strategy to produce sweeter tomato fruits with high sugar contents by fruit-specific expression of a single bZIP transcription factor gene. Plant Biotechnol. J. 14, 1116-1126. doi: 10.1111/pbi.12480

Schütze, K., Harter, K., and Chaban, C. (2008). Post-translational regulation of plant bZIP factors. Trends Plant Sci. 13, 247-255. doi: 10.1016/j.tplants.2008. 03.002

Shearer, H. L., Cheng, Y. T., Wang, L., Liu, J., Boyle, P., Després, C., et al. (2012). Arabidopsis clade I TGA transcription factors regulate plant defenses in an NPR1-independent fashion. Mol. Plant Microbe Interact. 25, 1459-1468. doi: 10.1094/MPMI-09-11-0256

Sibéril, Y., Doireau, P., and Gantet, P. (2001). Plant bZIP G-box binding factors. Modular structure and activation mechanisms. Eur. J. Biochem. 268, 5655-5666. doi: 10.1046/j.0014-2956.2001.02552.x

Sornaraj, P., Luang, S., Lopato, S., and Hrmova, M. (2016). Basic leucine zipper (bZIP) transcription factors involved in abiotic stresses: a molecular model of a wheat bZIP factor and implications of its structure in function. Biochim. Biophys. Acta 1860, 46-56. doi: 10.1016/j.bbagen.2015.10.014

Sparkes, I. A., Runions, J., Kearns, A., and Hawes, C. (2006). Rapid, transient expression of fluorescent fusion proteins in tobacco plants and generation of stably transformed plants. Nat. Protoc. 1, 2019-2025. doi: 10.1038/nprot. 2006.286

van Verk, M. C., Neeleman, L., Bol, J. F., and Linthorst, H. J. (2011). Tobacco transcription factor NtWRKY12 interacts with TGA2.2 in vitro and in vivo. Front. Plant Sci. 2:32. doi: 10.3389/fpls.2011.00032

Wang, W., Feng, B., Xiao, J., Xia, Z., Zhou, X., Li, P., et al. (2014). Cassava genome from a wild ancestor to cultivated varieties. Nat. Commun. 5:5110. doi: 10.1038/ncomms6110

Wang, Z., Cheng, K., Wan, L., Yan, L., Jiang, H., Liu, S., et al. (2015). Genome-wide analysis of the basic leucine zipper (bZIP) transcription factor gene family in six legume genomes. BMC Genomics 16:1053. doi: 10.1186/s12864-015-2258-x

Wei, K., Chen, J., Wang, Y., Chen, Y., Chen, S., Lin, Y., et al. (2012). Genomewide analysis of bZIP-encoding genes in maize. DNA Res. 19, 463-476. doi: 10.1093/dnares/dss026

Wei, Y., Hu, W., Wang, Q., Liu, W., Wu, C., Zeng, H., et al. (2016). Comprehensive transcriptional and functional analyses of melatonin synthesis genes in cassava reveal their novel role in hypersensitive-like cell death. Sci. Rep. 6:35029. doi: 10.1038/srep35029

Wei, Y., Liu, G., Bai, Y., Xia, F., He, C., and Shi, H. (2017). Two transcriptional activators of $\mathrm{N}$-acetylseronin $\mathrm{O}$-methyltransferase 2 and melatonin in cassava. J. Exp. Bot. 68, 4997-5006. doi: 10.1093/jxb/erx305 
Wydra, K., Banito, A., and Kpemoua, K. E. (2007). Characterization of resistance of cassava genotypes to bacterial blight by evaluation of leaf and systemic symptoms in relation to yield in different ecozones. Euphytiea 155, 337-348. doi: 10.1007/s10681-006-9335-9

Xu, J., Duan, X., Yang, J., Beeching, J. R., and Zhang, P. (2013). Enhanced reactive oxygen species scavenging by overproduction of superoxide dismutase and catalase delays postharvest physiological deterioration of cassava storage roots. Plant Physiol. 161, 1517-1528. doi: 10.1104/pp.112.212803

Xu, Z., Ali, Z., Xu, L., He, X., Huang, Y., Yi, J., et al. (2016). The nuclear protein GmbZIP110 has transcription activation activity and plays important roles in the response to salinity stress in soybean. Sci. Rep. 6:20366. doi: 10.1038/ srep 20366

Zeng, C., Chen, Z., Xia, J., Zhang, K., Chen, X., Zhou, Y., et al. (2014). Chilling acclimation provides immunity to stress by altering regulatory networks and inducing genes with protective functions in cassava. BMC Plant Biol. 14:207. doi: 10.1186/s12870-014-0207-5

Zha, L., Liu, S., Liu, J., Jiang, C., Yu, S., Yuan, Y., et al. (2017). DNA methylation influences chlorogenic acid biosynthesis in Lonicera japonica by mediating LjbZIP8 to regulate phenylalanine ammonia-lyase 2 expression. Front. Plant Sci. 8:1178. doi: 10.3389/fpls.2017.01178

Zhang, F., Fu, X., Lv, Z., Lu, X., Shen, Q., Zhang, L., et al. (2015). A basic leucine zipper transcription factor, AabZIP1, connects abscisic acid signaling with artemisinin biosynthesis in Artemisia annua. Mol. Plant 8, 163-175. doi: 10.1016/j.molp.2014.12.004
Zhao, J., Guo, R., Guo, C., Hou, H., Wang, X., and Gao, H. (2016) Evolutionary and expression analyses of the apple basic leucine zipper transcription factor family. Front. Plant Sci. 7:376. doi: 10.3389/fpls.2016. 00376

Zhao, P., Liu, P., Shao, J., Li, C., Wang, B., Guo, X., et al. (2015). Analysis of different strategies adapted by two cassava cultivars in response to drought stress: ensuring survival or continuing growth. J. Exp. Bot. 66, 1477-1488. doi: 10.1093/jxb/eru507

Zong, W., Tang, N., Yang, J., Peng, L., Ma, S., Xu, Y., et al. (2016). Feedback regulation of ABA signaling and biosynthesis by a bZIP transcription factor targets drought-resistance-related genes. Plant Physiol. 171, 2810-2825. doi: $10.1104 /$ pp.16.00469

Conflict of Interest Statement: The authors declare that the research was conducted in the absence of any commercial or financial relationships that could be construed as a potential conflict of interest.

Copyright (c) $2017 \mathrm{Li}, \mathrm{Fan}, \mathrm{Hu}, \mathrm{Liu}, \mathrm{Wei}, \mathrm{He}$ and Shi. This is an open-access article distributed under the terms of the Creative Commons Attribution License (CC BY). The use, distribution or reproduction in other forums is permitted, provided the original author(s) or licensor are credited and that the original publication in this journal is cited, in accordance with accepted academic practice. No use, distribution or reproduction is permitted which does not comply with these terms. 